\title{
CLINICAL PRACTICE GUIDELINE
}

\section{Colorectal Carcinoma}

The Management of Polyps, (Neo)Adjuvant Therapy, and the Treatment of Metastases

Wolff Schmiegel, Christian Pox, Dirk Arnold, Rainer Porschen,

Claus Rödel, Anke Reinacher-Schick

\section{SUMMARY}

Background: Colorectal carcinoma (CRC) is the second most common type of cancer in Germany. In view of recent major changes in the diagnosis and treatment of CRC, the S3 guideline for CRC published in its full version in $\mathbf{2 0 0 4}$ was partially updated in $\mathbf{2 0 0 8}$ and again in 2009.

Method: The literature was systematically searched for all articles published from 2004 onward concerning polyp management, (neo-)adjuvant treatment, and treatment of metastatic disease. Evidence-based recommendations were developed in a consensus conference.

Results: For some patients who have undergone polypectomy, the time to follow-up with colonoscopy can be lengthened. In UICC stage III colon cancer, adjuvant chemotherapy with an oxaliplatin-based regimen is recommended. In stage II colon cancer, adjuvant chemotherapy should be considered mainly when risk factors are present. In stages II and III, neo-adjuvant therapy should be given before resection in rectal cancer. In patients with metastatic disease, the use of all possible treatment options results in a median overall survival time of 24 months. In some patients with primarily non-resectable liver metastases, systemic treatment may enable a secondary, potentially curative resection. Therapeutic agents are chosen individually on the basis of clinical factors including the goal of treatment, the patient's general condition, and tumor molecular markers.

Conclusion: The S3 guideline contains evidence-based recommendations for the diagnosis and treatment of colorectal carcinoma. Broad implementation of the guideline will be essential for improved patient care.

Key words: colorectal carcinoma, polyps, adjuvant therapy, cancer treatment, palliative treatment

Gite this as: Dtsch Arztebl Int 2009; 106(51-52): 843-8 DOl: 10.3238/arztebl.2009.0843 olorectal carcinoma (CRC) is the second most common type of cancer in Germany, with an incidence of more than 70000 cases per year. About 30000 persons die each year as a result of this disease (1). The individual lifetime risk of developing colorectal carcinoma is 5\% (2). The S3 guidelines of the Oncology Guideline Program of the Association of the Scientific Medical Societies in Germany (Arbeitsgemeinschaft der wissenschaftlichen medizinischen Fachgesellschaften e.V., AWMF), German Cancer Aid (Deutsche Krebshilfe e.V., DKH), and the German Cancer Society (Deutsche Krebsgesellschaft, DKG) are intended to provide evidence-based recommendations derived from a consensus of expert panels. All medical societies dealing with the diagnosis and treatment of CRC, and relevant patient organizations, were involved in the guideline development process. The broad implementation of the guideline in patient care will be the next step; to this end, we present in this article an abridged version of the S3 guideline for CRC, as last updated in 2008. There is updated information in topic groups IV (polyp management), VI (adjuvant and neoadjuvant therapy), and VII (the treatment of metastatic disease and palliative care). All of the recommendations and changes in the field that are relevant to clinical practice are described and explained here. The unabridged version of the 2008 S3 guideline update has been published in the Zeitschrift für Gastroenterologie (3), while the full version of the S3 guideline 2004/2008 can be downloaded from the homepages of the AWMF, the DGVS, and the DKG.

\section{Methods}

Delegates from 14 medical societies, working groups, and self-help groups participated in the updating of the guideline (eBoxes 1 and 2).

\section{Systematic literature search}

In February 2007, the guideline secretariat carried out a search for literature published from 2004 to January 2007; the search was repeated in March 2008. The Medline and Cochrane databases were searched for complete publications, while the electronic database of the American Society of Clinical Oncology (ASCO) (www.asco.org) was searched for abstracts from scientific meetings. Abstracts are permitted in the updated guideline for the first time and are designated by an 


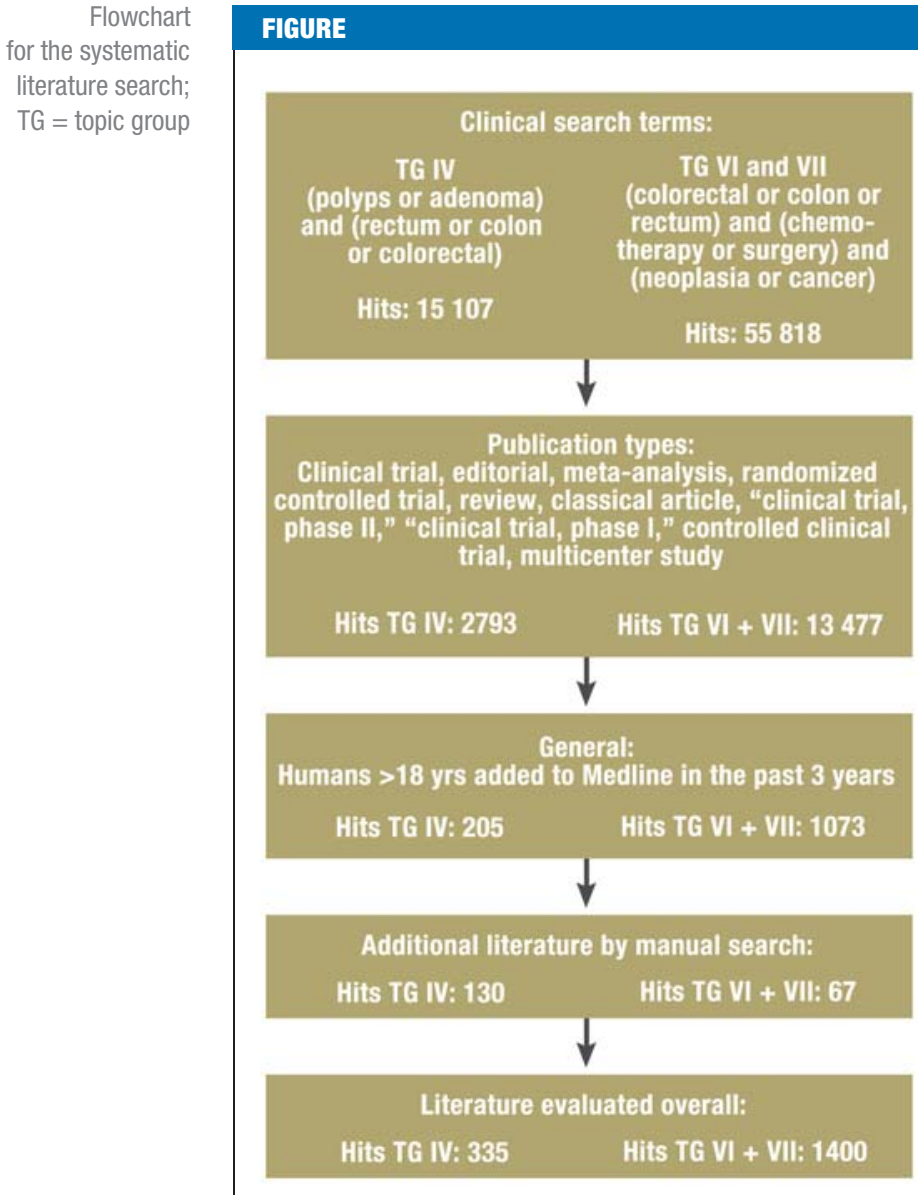

asterisk $(*)$. The major search terms, the search terms for topic groups IV and VI/VII, and the numbers of hits in each area are shown in the Figure. A further selection was carried out with the aid of defined exclusion criteria and a manual search.

\section{Consensus process, classification of evidence strength, and continued writing of the guide- line- the 2009 amendment}

Further information on the method by which the guideline was produced can be found in eBox 3. The 2009 amendment to the guideline, dealing with the topic of adjuvant therapy in elderly patients, came about because of safety considerations and is discussed here as well.

\section{Endoscopy and polyp management General principles}

A large majority of colorectal carcinomas arise from adenomatous polyps (the adenoma-carcinoma sequence). Thus, the removal of adenomas can prevent the development of carcinoma (5). Persons with adenomas have a $40 \%$ to $50 \%$ risk of developing recurrent adenomas (6); this is the rationale for recommending follow-up endoscopy after adenoma removal.
Follow-up endoscopy is both costly and personnelintensive.

Most adenomas never give rise to a carcinoma. The risk of malignant degeneration depends on the size of the adenoma, the histological findings, and the degree of intraepithelial neoplasia. The highest risk of degeneration is present when the adenoma is $10 \mathrm{~mm}$ in size or larger, and/or villous histology is present, and/or there is high-grade intraepithelial neoplasia (advanced adenomas): Degeneration occurs in $25 \%$ to $43 \%$ of such cases within 10 years (7). The risk of progression from adenomas that are not of these advanced types has not been quantified, but is presumably much lower. Recommendations for follow-up endoscopy are a function of the risk of development of advanced adenomas and carcinomas. Such recommendations are based on the assumption that a complete, high-quality baseline endoscopy has been carried out and that all detected lesions have been totally removed.

\section{Recommendations for follow-up endoscopy after adenoma removal}

When one or two small, tubular adenomas $(<10 \mathrm{~mm})$ have been removed, a follow-up colonoscopy five years later is adequate (recommendation grade [RG] A, evidence strength [ES] 2b). As this is the most common constellation in clinical practice, this recommendation represents a major change from the previous guideline, in which follow-up endoscopy at three years was recommended. The risk of detection of advanced adenomas and carcinomas in this group of patients is no higher than that in persons whose index colonoscopy revealed no adenomas at all (8).

When three or more adenomas, at least one adenoma of size $10 \mathrm{~mm}$ or more, or adenomas with villous or high-grade intraepithelial neoplasia have been removed, follow-up colonoscopy at three years is recommended (RG A, ES 1b).

Patients with ten or more adenomas are an exception to the above recommendations for follow-up at three or five years. These patients have a markedly higher risk of developing carcinoma and should therefore be followed up earlier. Often, the first follow-up colonoscopy is performed one year after the index procedure.

When sessile or flat adenomas are removed in multiple pieces (in so-called "piecemeal” fashion), the rate of recurrence is markedly higher, particularly with larger adenomas (9\% to 28\%) (9). Thus, in such cases, the local findings should be followed-up early (in two to six months). It is good practice to label the site of removal with an indelible mark.

\section{Recommendations for serrated polyps}

Recent studies have shown that, aside from classic adenomas, serrated polyps (sessile serrated adenomas [SSA], mixed mucosal polyps [mixed polyps], and traditional serrated adenomas [TSA]) are of special significance (10). These lesions, too, are associated with an elevated risk of malignant degeneration via the socalled serrated cancer development pathway. After they 
are completely removed, follow-up colonoscopy at three years is recommended (RG A, ES 4).

In contrast, after the removal of singular hyperplastic polyps, no special follow-up examination is required; i.e., the same ten-year follow-up interval is recommended as after a colonoscopy with normal findings (RG A, ES 3b).

\section{Polypectomy under anticoagulation}

The number of patients receiving long-term anticoagulant therapy is increasing. Dual inhibition of platelet aggregation with acetylsalicylic acid (ASA) and clopidogrel is of special significance, as it markedly elevates the risk of bleeding and therefore contraindicates polypectomy (11). On the other hand, polypectomy can be carried out without any major increase in the risk of bleeding if the patient is being treated with ASA alone (12). After consideration of the respective indications for polypectomy and dual inhibition of platelet aggregation, polypectomy should be timed during an interval of ASA monotherapy in which clopidogrel has been temporarily stopped, if this is feasible.

\section{Recommendations for malignant polyps (T1 carcinoma)}

A pT1 carcinoma is sometimes found in an endoscopically removed polyp. The prognosis of such carcinomas varies considerably, depending on the situation; the most important variable is the probability that lymph node metastases are already present. The overall group of $\mathrm{T} 1$ carcinomas has a lymph node metastasis rate $(\mathrm{N}+)$ of $0 \%$ to $20 \%$ (13). In the "low-risk" situation (G1 or G2, no lymphatic invasion [L0]), the rate of metastasis is $0 \%$ to $4 \%$. In such cases, if it is certain that an R0 polyp removal has been performed, there is no need for surgical re-resection. On the other hand, in the "high-risk" situation (G3 or G4 or lymphatic invasion [L1]), oncological criteria imply the need for additional resection, even after definite R0 removal (RG A, ES 3a, consensus).

\section{Adjuvant and neoadjuvant therapy}

Because of the special anatomical characteristics of the rectum, local recurrences of carcinoma are much more common in the rectum than in the colon. The treatment strategies for perioperative therapy for carcinoma in these two locations differ accordingly. Colon carcinoma is treated with chemotherapy after surgery (adjuvant chemotherapy), while rectum carcinoma is treated preoperatively with radio-(chemo-)therapy (neoadjuvant therapy).

\section{The adjuvant therapy of colon carcinoma}

General principles-The five-year survival rate of patients who have undergone resection of colon carcinoma (UICC stage I-III) with curative intent, independent of tumor stage, ranges from $44 \%$ to $93 \%$ (14). Recurrent cancer, predominantly in the form of hematogenous metastatic disease, usually arises within two years of the initial diagnosis. The goal of postoperative (adjuvant) therapy is to eliminate disseminated tumor

\section{TABLE 1}

Adjuvant therapy for colon carcinoma: stage-dependent recommendations of the S3 guideline, and special cases

\begin{tabular}{l|l|l|l|l}
\hline I & None & N/A & N/A & N/A \\
\hline II without RF & May be used & O/1b & Fluoropyrimidine & QUASAR (18) \\
\hline II with RF & Recommended & B/3 & Fluoropyrimidine & \\
\hline III & $\begin{array}{l}\text { Strongly recom- } \\
\text { mended }\end{array}$ & A/1 & $\begin{array}{l}\text { Oxaliplatin/5FU } \\
\text { (FOLFOX) }\end{array}$ & MOSAIC (16) \\
\hline Age $<70$ & $\begin{array}{l}\text { Strongly recom- } \\
\text { mended }\end{array}$ & A/1 & $\begin{array}{l}\text { Fluoropyrimidine } \\
\text { (5-FU) }\end{array}$ & Pooled analysis (19) \\
\hline Age $>70$ & $\begin{array}{l}\text { To be used judi- } \\
\text { ciously }\end{array}$ & B & $\begin{array}{l}\text { Oxaliplatin com- } \\
\text { binations* }\end{array}$ & $\begin{array}{l}\text { NSABP C-08 (e1) } \\
\text { Petacc-8, ACCENT } \\
\text { (e2) }\end{array}$ \\
\hline
\end{tabular}

*Amendment to the S3 guideline, 2009; $\mathrm{RF}$, risk factors, RG, recommendation grade; $E S$, evidence strength; N/A, not available

cells and thereby improve long-term survival. The essential prerequisite for the planning of adjuvant therapy is an R0 resection with adequate histopathological staging, including a determination of lymph node status in at least 12 examined nodes. Adjuvant therapy is not indicated for patients with stage I colon carcinoma; in stage III, adjuvant therapy has been considered the standard treatment for many years. The indication for adjuvant therapy in stage II depends on the presence of certain risk factors (Table 1). The indication should always be considered in the light of the patient's general condition, life expectancy, and any accompanying illnesses.

Adjuvant therapy in stage III-Patients who have undergone resection of a stage III colon carcinoma with curative intent should receive adjuvant therapy (RG A, ES 1, strong consensus), as this has been shown to result in a $15 \%$ to $20 \%$ improvement in long-term survival $(15,16)$. A regime of intravenously infused 5fluorouracil (5-FU) should be given in combination with oxaliplatin, as this has been shown to improve survival as compared to 5-FU/folic acid (FA) alone (16). If treatment with oxaliplatin is contraindicated, fluoropyrimidines should be given as monotherapy; oral capecitabin is preferred to intravenously infused 5-FU for this purpose (17). 5-FU bolus protocols are obsolete.

Adjuvant therapy in stage II-Decisions regarding treatment in stage II depend on the presence or absence of clinical factors that elevate the risk of recurrence (T4 stage, tumor perforation/rupture, emergency surgery, fewer than 12 lymph nodes studied). If any of these risk factors are present, adjuvant therapy with a fluoropyrimidine should be considered (RG B, ES 3, strong consensus). If no risk factors are present, adjuvant therapy with a fluoropyrimidine can still be given (RG 0, ES 1, strong consensus). The absolute survival advantage 


\section{Therapeutic algorithm for patients in UICC Stage IV}

Subgroup definition by clinical situation/goal of treatment

1. Patients with primarily resectable hepatic and/or pulmonary metastases

2. Patients with an indication for intensified systemic therapy

- Patients with hepatic and/or pulmonary metastases that are potentially resectable after response to neoadjuvant therapy (and clinically operable patients)

- Patients with tumor-related symptoms, organ complications, or rapid progression

3. Patients for whom less intensive therapy is an option

- Patients with multiple metastases not amenable to resection after regression of the metastases, without tumor-related symptoms, organ complications, or severe comorbidity

Strong consensus radiotherapy is not fully clear. At present, the prognosis with respect to survival is mainly determined by the presence or absence of distant metastases.

\section{Perioperative (neoadjuvant/adjuvant) radio- or radiochemotherapy}

In UICC stage II or III, preoperative therapy is indicated. This can be applied either as short-term radiotherapy alone ( $5 \times 5 \mathrm{~Gy}$ ) or as combined radiochemotherapy over five weeks (45 to 50.4 Gy in 25 to 28 fractions) (RG A, ES 1b, strong consensus); combined radiochemotherapy is preferably given before, rather than after, surgery, as this will significantly lower both the local recurrence rate and the toxicity of treatment (20). The choice of preoperative treatment modality depends on the goal of treatment. If the purpose is to shrink the tumor (e.g., in the case of a T4 tumor, a T3 tumor located near the mesorectal resection line, or a low-lying tumor, where preservation of the sphincter is an objective), then combined radiochemotherapy with 5-FU with or without FA is preferable (RG A, ES 1b, strong consensus). There is no standard recommendation for primarily metastatic rectal carcinoma. In such cases, either systemic chemotherapy or intensified radiochemotherapy (e.g., with oxaliplatin) can be used, depending on the patient's clinical manifestations and the distribution of the tumor burden.

If the imaging studies reveal that the tumor is limited to the bowel wall (cT1/2) and lymph node involvement is questionable, surgery can be performed as the primary procedure. If stage II or III disease is then documented postoperatively, the patient (who received no neoadjuvant treatment before surgery) can be treated with adjuvant radiochemotherapy (with 5-FU) (RG A, ES 1b, strong consensus). After neoadjuvant radiochemotherapy, adjuvant chemotherapy with 5-FU with or without FA should be given, regardless of the postoperative histological tumor stage (even if the patient is in complete remission) (RG A, ES 1b, strong consensus).

\section{Therapeutic recommendations for metastatic disease and in the palliative situation}

The treatment of metastatic CRC has one of two goals, depending on the patient's clinical condition. Palliative therapy aims to prolong survival while preserving or improving the quality of life, whereas organ metastases (usually hepatic metastases) can be resected with curative intent. The reported 5-year survival rate after the $\mathrm{R} 0$ resection of hepatic metastases is $20 \%$ to $30 \%$. This is also the case when the metastasis is initially nonresectable: in up to one-quarter of patients treated with systemic therapy, organ metastases shrink to such an extent that a potentially curative operation can be considered. Thus, treatment is chosen depending on the clinical subgroup to which the patient belongs (Box).

Clinical group 1-resectable hepatic and pulmonary metastases The recommendations for primarily resectable metastases (group 1) are summarized in Table 2. These 
recommendations are based on trials of adjuvant therapy (21) and of neoadjuvant and adjuvant therapy (22). The risk of recurrence can be estimated with the aid of the FONG score, which incorporates the following parameters: primary tumor with positive nodes, occurrence of metastases within 12 months of initial diagnosis, metastasis larger than $5 \mathrm{~cm}$, more than one metastasis, and CEA > $200 \mathrm{ng} / \mathrm{mL}$.

\section{Clinical groups 2 and 3 -general recommendations}

If primarily nonresectable metastases are present (groups 2 and 3), systemic treatment is generally indicated, as this has been shown to improve survival in comparison to "best supportive care" (median survival of about six months). The median survival with modern combination therapy is about two years. The patient's age is not a contraindication, as long as no major accompanying illnesses are present (RG A, ES 1a, strong consensus). If systemic therapy is indicated, the primary tumor can be left in situ, unless clinically relevant hemorrhage or stenosis is present (RG 0, ES 4, strong consensus). While under treatment, the patient should have access to all available medications with documented efficacy (RG A, ES 5, strong consensus). These include the fluoropyrimidines (as an infusion or per os), oxaliplatin and irinotecan as chemotherapy, and bevacizumab (antibodies against vascular endothelial growth factor [VEGF]) and antibodies against the epidermal growth factor receptor (EGFR; cetuximab or panitumumab) as molecular therapy.

\section{Clinical group 2-Indications for intensified therapy Patients with potentially resectable metastases}

Patients with primarily nonresectable (hepatic) metastases that might become resectable after a reduction in size should receive the most effective systemic combination therapy available (RG A, ES 4, strong consensus) (eTable 2). While receiving chemotherapy, these patients should be regularly evaluated for resectability, and the operation should be performed as soon as a R0 resection becomes possible, because perioperative morbidity increases with the duration of chemotherapy. In other words, surgery should not be delayed until clinically complete remission has been achieved.

\section{Patients with tumor-related clinical manifestations, organ complications, or rapid progression}

Patients in this group should receive combination therapy that is as effective as possible while taking their general condition into account (intensified therapy) (RG B, ES 5, strong consensus). This consists of dual chemotherapy with or without monoclonal antibodies (bevacizumab and cetuximab have been approved for first-line therapy; panitumumab is expected to be approved in 2010). In general, chemotherapy is continued until the tumor demonstrably progresses. If there is a marked tumor response, however, chemotherapy can be de-escalated after intense initial therapy, in order to hold its side effects to a minimum (23). Adequate

\section{TABLE 2}

Summarized recommendations for patients in Stage IV, Group 1 (resectable metastases)

\begin{tabular}{l|l|l|l}
\hline Recommendation & RG & ES & Consensus \\
$\begin{array}{l}\text { Resection of metastases, } \\
\text { if resectable }\end{array}$ & A & $3 \mathrm{~b}$ & strong \\
\hline $\begin{array}{l}\text { Evaluation by an experienced } \\
\text { surgeon }\end{array}$ & & & strong \\
\hline $\begin{array}{l}\text { PET when the FONG score is } \\
\text { above 2 }\end{array}$ & $\mathrm{B}$ & 3 & strong \\
\hline $\begin{array}{l}\text { Perioperative (neoadjuvant/ } \\
\text { adjuvant) chemotherapy in } \\
\text { exceptional cases }\end{array}$ & 0 & 3 & strong \\
\hline Adjuvant chemotherapy & $\mathrm{B}$ & 2 & strong \\
\hline
\end{tabular}

PET, positron emission tomography $R G$, recommendation grade; ES, evidence strength

evidence is not (yet) available to support a complete pause in therapy (RG B, ES 1b, consensus).

\section{Clinical group 3-Patients for whom less intensive therapy is an option}

Patients who have multiple metastases that would not be amenable to resection even if shrunken by chemotherapy, and who do not suffer from tumor-related symptoms, organ complications, or severe comorbidity, can also be initially treated with a single chemotherapeutic agent as first-line therapy (RG 0, ES 1, strong consensus). In randomized trials, sequential treatment with monotherapy followed by combination therapy yielded a comparable survival rate to that of primary combination therapy $(24,25)$.

\section{Acknowledgement}

The updating of the S3 guideline on colorectal carcinoma was supported by German Cancer Aid (Deutsche Krebshilfe e.V.). We thank all members of the consensus conference for their participation as unpaid volunteers. In particular, we thank Professor Kopp of the AWMF for her help with methodology and content.

\section{Conflict of interest statement}

Authors Schmiegel, Rödel and Pox state that they have no conflict of interest as defined by the guidelines of the International Committee of Medical Journal Editors. Author Porschen has received lecture honoraria from Sanofi-Aventis, Pfizer and Roche as well as study support from Roche and Sanofi. Author Arnold has received lecture honoraria from Roche, Sanofi-Aventis, Pfizer, Merck and Amgen, payment of travel expenses by Roche, Sanofi-Aventis, Pfizer and Merck, and study support from Roche, Sanofi-Aventis and Pfizer. Author Reinacher-Schick has received lecture honoraria from Amgen, Roche, Sanofi and Pfizer and project support from Roche and Sanofi.

Manuscript submitted on 16 November 2009; revised version accepted on 18 November 2009.

Translated from the original German by Ethan Taub, M.D.

\section{REFERENCES}

1. Robert Koch-Institut. Krebs in Deutschland 2008.www.rki.de

2. Screening for colorectal cancer: U.S. Preventive Services Task Force recommendation statement. Ann Intern Med 2008; 149: 627-37.

3. Schmiegel W, Reinacher-Schick A, Arnold D, et al.: S3-Leitlinie „Kolorektales Karzinom" - Aktualisierung 2008. Z Gastroenterol 2008; 46: 799-840. 
4. Schönhofer B, Kuhlen R, Neumann P, et al.: Clinical practice guideline: non-invasive mechanical ventilation as treatment of acute respiratory failure [Klinische Leitlinie. Nicht invasive Beatmung bei respiratorischer Insuffizienz]. Dtsch Arztebl Int 2008; 105(24): 424-33.

5. Winawer SJ, Zauber AG, Ho MN, et al.: Prevention of colorectal cancer by colonoscopic polypectomy. The National Polyp Study Workgroup. N Engl J Med 1993; 329: 1977-81.

6. Martinez ME, Baron JA, Lieberman DA, et al.: A pooled analysis of advanced colorectal neoplasia diagnoses after colonoscopic polypectomy. Gastroenterology 2009; 136: 832-41.

7. Brenner $\mathrm{H}$, Hoffmeister M, Stegmaier $\mathrm{C}$, et al.: Risk of progression of advanced adenomas to colorectal cancer by age and sex: estimates based on 840149 screening colonoscopies. Gut 2007; 56: $1585-9$.

8. Lieberman DA, Weiss DG, Harford WV, et al.: Five-year colon surveillance after screening colonoscopy. Gastroenterology 2007; 133: 1077-85.

9. Higaki S, Hashimoto S, Harada K, et al.: Long-term follow-up of large flat colorectal tumors resected endoscopically. Endoscopy 2003; 35: 845-9.

10. Jass JR: Classification of colorectal cancer based on correlation of clinical, morphological and molecular features. Histopathology 2007; 50: 113-30.

11. Ernst A, Eberhardt R, Wahidi M, Becker HD, Herth FJ: Effect of routine clopidogrel use on bleeding complications after transbronchial biopsy in humans. Chest 2006; 129: 734-7.

12. Yousfi M, Gostout CJ, Baron TH, et al.: Postpolypectomy lower gastrointestinal bleeding: potential role of aspirin. Am J Gastroenterol 2004; 99: 1785-9.

13. Deinlein $P$, Reulbach U, Stolte M, Vieth M: Risikofaktoren der lymphogenen Metastasierung von kolorektalen pT1-Karzinomen. Pathologe 2003; 24: 387-93.

14. O'Connell JB, Maggard MA, Ko CY: Colon cancer survival rates with the new American Joint Committee on Cancer sixth edition staging. J Natl Cancer Inst 2004; 96: 1420ff.

15. Moertel CG, Fleming TR, Macdonald JS, et al.: Fluorouracil plus levamisole as effective adjuvant therapy after resection of stage III colon carcinoma: a final report. Ann Intern Med 1995; 122: 321-6.

16. André T, Boni C, Navarro M, et al.: Improved overall survival with oxaliplatin, fluorouracil, and leucovorin as adjuvant treatment in stage II or III colon cancer in the MOSAIC trial. J Clin Oncol 2009; 27: 3109-16.
17. Twelves $\mathrm{C}$, et al.: Capecitabine as adjuvant treatment for stage III colon cancer. N Engl J Med 2005; 352: 2696-704.

18. Quasar Collaborative Group Gray R, Barnwell J, Mc Conkey C, et al.: Adjuvant chemotherapy versus observation in patients with colorectal cancer: a randomised study. Lancet 2007; 370: 2020-9.

19. Sargent DJ, Goldberg RM, Jacobson SO, et al.: A pooled analysis of adjuvant chemotherapy for resected colon cancer in elderly patients. N Engl J Med 2001; 345: 1091-7.

20. Sauer R, Becker H, Hohenberger W, et al.: Preoperative versus postoperative chemoradiotherapy for rectal cancer. N Engl J Med 2004; 351: 1731-40.

21. Mitry E, Fields AL, Bleiberg H, et al.: Adjuvant chemotherapy after potentially curative resection of metastases from colorectal cancer: a pooled analysis of two randomized trials. J Clin Oncol 2008; 26: 4906-11.

22. Nordlinger B, Sorbye $H$, Glimelinus B, et al.: Perioperative chemotherapy with FOLFOX4 and surgery versus surgery alone for resectable liver metastases from colorectal cancer (EORTC Intergroup trial 40 983): a randomised controlled trial. Lancet 2008; 371: 1007-16.

23. Tournigand $\mathrm{C}$, Cervantes $\mathrm{A}$, Figer $\mathrm{A}$, et al.: OPTIMOX1: a randomized study of FOLFOX4 or FOLFOX7 with oxaliplatin in a stop-and-go fashion in advanced colorectal cancer-a GERCOR study. J Clin Oncol 2006; 24: 394-400.

24. Koopman M, Antonini NF, Douma J, et al.: Sequential versus combination chemotherapy with capecitabine, irinotecan, and oxaliplatin in advanced colorectal cancer (CAIRO): a phase III randomised controlled trial. Lancet 2007; 370: 135-42.

25. Seymour MT, Maughan TS, Ledermann JA, et al.: Different strategies of sequential and combination chemotherapy for patients with poor prognosis advanced colorectal cancer (MRC FOCUS): a randomised controlled trial. Lancet 2007; 370: 143-52.

\section{Corresponding author}

Prof. Dr. med. Wolff Schmiegel

Medizinische Klinik, Ruhr-Universität Bochum, Knappschaftskrankenhaus

In der Schornau 23-25

44892 Bochum, Germany

meduni-kkh@rub.de,Internet: www.medunikkh.de

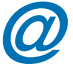

For e-references please refer to: www.aerzteblatt-international.de/ref5109

eBoxes and eTables available at: www.aerzteblatt-international.de/article09m843 


\section{CLINICAL PRACTICE GUIDELINE}

\section{Colorectal Carcinoma}

The Management of Polyps, (Neo)Adjuvant Therapy, and the Treatment of Metastases

Wolff Schmiegel, Christian Pox, Dirk Arnold, Rainer Porschen,

Claus Rödel, Anke Reinacher-Schick

\section{E-REFERENCES}

e1. Allegra CJ, Yothers G, O'Connell MJ, et al.: Initial safety report of NSABP C-08: a randomized phase III study of modified FOLFOX6 with or without bevacizumab for the adjuvant treatment of patients with stage II or III colon cancer. J Clin Oncol 2009; 27: 3385-90.

e2. Jackson McCleary NA, Meyerhardt J, Green E, et al.: Impact of older age on the efficacy of newer adjuvant therapies in $>12,500$ patients (pts) with stage II/III colon cancer: Findings from the ACCENT Database. J Clin Oncol 2009; 27: p15 (suppl; abstr 4010).

e3. Falcone A, et al.: Phase III trial of infusional fluorouracil, leucovorin, oxaliplatin, and irinotecan (FOLFOXIRI) compared with infusional fluorouracil, leucovorin, and irinotecan (FOLFIRI) as first-line treatment for metastatic colorectal cancer: the Gruppo Oncologico Nord Ovest. J Clin Oncol 2007; 25: 1670-6 (EBM-Grad: I b).

e4. Van Cutsem E, Köhne CH, Hitre E, et al.: Cetuximab and chemotherapy as initial treatment for metastatic colorectal cancer. NEJM 2009; 360: 1408-17.

e5. Saltz LB, et al.: Bevacizumab in combination with oxaliplatinbased chemotherapy as first-line therapy in metastatic colorectal cancer: a randomized phase III study. J Clin Oncol 2008; 26: 2013-9. 


\section{CLINICAL PRACTICE GUIDELINE}

\section{Colorectal Carcinoma}

The Management of Polyps, Neoadjuvant Therapy, and the Treatment of Metastases

Wolff Schmiegel, Christian Pox, Dirk Arnold, Rainer Porschen,

Claus Rödel, Anke Reinacher-Schick

\section{eBOX 1}

\section{Participating societies}

- Leading role in the development of the guideline: German Society for Digestive and Metabolic Diseases (Deutsche Gesellschaft für Verdauungs- und Stoffwechselkrankheiten, DGVS)

- German Society for General and Visceral Surgery (Deutsche Gesellschaft für Allgemein- und Viszeralchirurgie, DGAV)

- German Society for Hematology and Oncology (Deutsche Gesellschaft für Hämatologie und Onkologie, DGHO)

- German Society for Pathology (Deutsche Gesellschaft für Pathologie, DGP)

- German Society for Radiooncology (Deutsche Gesellschaft für Radioonkologie, DEGRO)

- Surgical Working Group on Oncology (Chirurgische Arbeitsgemeinschaft Onkologie, CAO-V) of the DGAV

- German Roentgen Society (Deutsche Röntgengesellschaft, DRG)

- German Joint Society for Clinical Chemistry and Laboratory Medicine (Deutsche Vereinte Gesellschaft für Klinische Chemie und Laboratoriumsmedizin, DGKL)

- German Society for Coloproctology (Deutsche Gesellschaft für Koloproktologie, DGK)

- Association of Stoma Patients and Persons with Intestinal Cancer (Vereinigung für Stomaträger und für Menschen mit Darmkrebs, the German ILCO)

- German Crohn's Disease and Ulcerative Colitis Association (Deutsche Morbus Crohn/Colitis ulcerosa Vereinigung, DCCV)

- German Society for Internal Medicine (Deutsche Gesellschaft für Innere Medizin, DGIM)

- Working Group on Oncology in Internal Medicine (Arbeitsgemeinschaft Internistische Onkologie, AIO) of the German Cancer Society (Deutsche Krebsgesellschaft, DKG)

- Association of the Scientific Medical Societies in Germany (Arbeitsgemeinschaft der wissenschaftlichen medizinischen Fachgesellschaften e.V., AWMF) 


\section{Coordinators and Members of the Topic Groups}

Topic Group IV

Endoscopy: Procedure and Polyp Management

\section{Coordinators:}

- Prof. Dr. W. Schmitt, Klinikum Neuperlach, München, DGVS

- Prof. Dr. J. F. Riemann, Klinikum der Stadt Ludwigshafen, DGVS

Members:

- Prof. Dr. G. Baretton, Institut für Pathologie, Universitätsklinikum Dresden, DGP

- PD Dr. S. Faiss, III. Medizinische Abteilung, Asklepios Klinik Barmbek, Hamburg, DGVS

- Prof. Dr. H. E. Gabbert, Institut für Pathologie, Universitätsklinikum Düsseldorf, DGP

- S. In der Smitten, DCCV-Bundesgeschäftsstelle, Leverkusen, DCCV

- Prof. J. Mössner, Medizinische Klinik und Poliklinik, Universitätsklinikum Leipzig, DGVS

- Prof. Dr. H. Neuhaus, Medizinische Klinik, Gastroenterologie, Evangelisches Krankenhaus Düsseldorf, DGVS

- Dr. G. Pommer, Praxis für Gastroenterologie, Oldenburg, DGVS/ DGK

- Dr. C. Pox, Medizinische Universitätsklinik,Knappschaftskrankenhaus, Ruhr-Universität Bochum, DGVS

- PD Dr. M. Reiser, Klinik für Innere Medizin, Paracelsusklinik Marl, DGVS

- PD Dr. K. Schoppmeyer, Medizinische Klinik und Poliklinik,Universitätsklinikum Leipzig, DGVS

- Dr. B. Schumacher, Medizinische Klinik, Gastroenterologie, Evangelisches Krankenhaus Düsseldorf, DGVS

- Prof. Dr. Ch. Wittekind, Institut für Pathologie, Universitätsklinikum Leipzig, DGP

Topic Group VI

Adjuvant und neoadjuvant therapy

Coordinators:

- Prof. Dr. R. Porschen, Klinik für Innere Medizin, Klinikum Bremen-Ost, DGVS

- Prof. Dr. R. Sauer, Klinik für Strahlentherapie, Universitätsklinikum Erlangen, DEGRO

\section{Members:}

- Dr. D. Arnold Medizinische Klinik IV, Universitätsklinikum Halle, DGHO

- Prof. Dr. W. Budach, Radioonkologie, Universitätsklinikum Düsseldorf, DEGRO

- PD Dr. G. Folprecht, Medizinische Klinik und Poliklinik, Universitätsklinikum Dresden, DGHO

- Prof. Dr. M. Geißler, Klinik für Onkologie, Gastroenterologie und Allg. Innere Medizin, Städtische Kliniken Esslingen, DGVS
- PD Dr. R. D. Hofheinz, III. Medizinische Klinik, Universitätsklinikum Mannheim, AIO

- Prof. Dr. C. H. Köhne, Klinik für Hämatologie und Onkologie, Klinikum Oldenburg, AIO

- Prof. Dr. K. H. Link, Chirurgisches Zentrum, Asklepios Paulinen Klinik Wiesbaden, DGAV, CAO-V

- Prof. Dr. C. Rödel, Klinik für Strahlentherapie, Universitätsklinikum Frankfurt am Main, DEGRO

- PD Dr. A. Reinacher-Schick, Medizinische Universitätsklinik, Knappschaftskrankenhaus, Ruhr-Universität Bochum, DGVS, AIO

- Prof. Dr. A. Tannapfel, Institut für Pathologie, Berufsgenossenschaftliches Universitätsklinikum Bergmannsheil, Ruhr-Universität Bochum, DGP

Topic Group VII

The therapeutic approach to metastatic disease

and palliation

Coordinators:

- Prof. Dr. H. J.Schmoll, Medizinische Klinik IV, Universitätsklinikum Halle, AlO

- PD Dr. U. Graeven, Medizinische Klinik I, Kliniken Maria Hilf, Mönchengladbach, DGVS/DGHO/AIO

\section{Members:}

- Prof. Dr. W.O. Bechstein, Klinik für Allgemeinchirurgie, Universitätsklinikum Frankfurt am Main, DGAV/CAO-V

- Dr. K. Eichler, Institut für Diagnostische und Interventionelle Radiologie, Universitätsklinikum Frankfurt am Main, DRG

- Prof. Dr. V. Heinemann, Medizinische Klinik und Poliklinik III, Klinikum der Universität München - Großhadern, AIO

- Prof. Dr. T. Höhler, Medizinische Klinik I, Prosper-Hospital, Recklinghausen, DGHO

- Dr. F. Overkamp, Onkologische Schwerpunktpraxis, Recklinghausen, DGHO

- Prof. Dr. S. Petrasch, Klinik für Innere Medizin, Wedau-Kliniken Duisburg, DGVS

- Prof. Dr. H.-R. Raab, Klinik für Allgemein- und Viszeralchirurgie, Klinikum Oldenburg, DGAV/CAO-V

- Prof. Dr. W. Schmiegel, Medizinische Universitätsklinik, Knappschaftskrankenhaus, Ruhr-Universität Bochum, DGVS, AIO

- Prof. Dr. T. Seufferlein, Medizinische Klinik II, Universitätsklinikum Halle, DGVS

- Dr. T. Trarbach, Westdeutsches Tumorzentrum, Uniklinikum Essen, AlO

- Prof. Dr. U. Vanhöfer, Zentrum für Innere Medizin, Kath. Marienkrankenhaus Hamburg, AIO

- Prof. Dr. T. Vogl, Institut für Diagnostische und Interventionelle Radiologie, Universitätsklinikum Frankfurt am Main, DRG 


\section{The method by which this guideline was produced}

\section{Consensus process}

The catalog of questions for the 2004 update concerning the three topic groups was revised and sent to the topic group members (Delphi method). The revised catalogs of questions were then answered. The consensus conference took place on 8 and 9 June 2007. Recommendations were discussed and modified in a nominal group process followed by a vote in plenary session. Topics on which no consensus was reached were dealt with afterward and voted upon by correspondence.

\section{Classification of evidence strength, recommendation grade, and consensus strength}

The evidence strengths (ES) of the studies underlying this guideline were classified according to the modified recommendations of the Centre for Evidence-Based Medicine, Oxford, UK (http://www.cebm.net/) (4). The recommendation grades (RG) were then derived from the evidence strengths ( $A$, strongly recommended; $B$, recommended; 0 , may be used). When there was disagreement, an external assessment of the literature and the evidence was performed by an independent expert in scientific methods (Prof. Kopp, Marburg, AWMF). The consensus strength (CS) reflected the percentage of participants agreeing to the recommendation (eTable 1). The resulting recommendations were sent to all persons who had taken part in the 2004 consensus conference and to the participating medical societies and organizations. On 11 July 2008, The manuscript was submitted to the Zeitschrift für Gastroenterologie for publication.

\section{Implementation, duration of validity, and updating}

The goal is for the recommendations of this S3 guideline to be implemented in certified intestinal cancer centers of the German Cancer Society (Deutsche Krebsgesellschaft, DKG) and other institutions whose quality indicators are based on these recommendations. At present, about $20 \%$ of patients newly diagnosed with intestinal cancer in Germany receive treatment in intestinal cancer centers. The 2008 update is expected to remain valid for three to four years. Furthermore, a current addendum (November 2009) is being published together with this article. The addendum is necessary in view of new considerations regarding the safety of adjuvant therapy in the elderly.

\section{eBOX 4}

\section{Adjuvant therapy in the elderly: an amendment to the 2009 guideline}

\section{Background information}

When treating elderly patients, the physician should consider the patient's comorbidities and general contraindications as well as the lower life expectancy, which lowers the overall benefit of adjuvant therapy. With respect to safety, the toxicity assessment of the NSABP C-08 trial, in which FOLFOX was compared to FOLFOX combined with bevacizumab for patients in UICC stage II or III disease, revealed that fatal serious adverse events (SAE's) occurred more frequently in patients over age 70 in both arms of the study (e1). The PETACC-8 trial (FOLFOX vs. FOLFOX + cetuximab) was stopped for patients over age 70 because of a treatment-associated elevation of mortality, but these patients' comorbidities and the precise causes of their deaths remain unclear. The updated ACCENT data analysis, a combined analysis of adjuvant trials concerning treatment with oxaliplatin, irinotecan, or oral fluoropyrimidines, revealed that oxaliplatin combinations gave patients over 70 no benefit with respect to either disease-free or overall survival. A comparable trend was seen with the use of oral fluoropyrimidines (e2). 


\section{CLINICAL PRACTICE GUIDELINE}

\section{Colorectal Carcinoma}

The Management of Polyps, (Neo)Adjuvant Therapy, and the Treatment of Metastases

Wolff Schmiegel, Christian Pox, Dirk Arnold, Rainer Porschen,

Claus Rödel, Anke Reinacher-Schick

\begin{tabular}{|c|c|}
\hline \multicolumn{2}{|c|}{ Classification of consensus strength $*^{1}$} \\
\hline Consensus strength & Percent agreement \\
\hline Strong consensus & $>95 \%$ of participants \\
\hline Consensus & $75 \%-95 \%$ of participants \\
\hline Majority agreement & $50 \%-75 \%$ of participants \\
\hline No consensus & $<50 \%$ of participants \\
\hline
\end{tabular}

\section{eTABLE 2}

Response rates and survival of patients after attainment of secondary resectability under combination therapy* ${ }^{1}$

\begin{tabular}{|c|c|c|c|c|c|c|}
\hline Reference & N & Chemotherapy regime & Response rate (\%) & $\begin{array}{l}\text { R0 resection rate } \\
(\%)\end{array}$ & $\begin{array}{l}\text { Long-term survival } \\
\text { after resection }\end{array}$ & EBM grade \\
\hline Falcone $2007 \star^{2}$ (e3) & 244 & FOLFIRI vs. FOLFOXIRI & $\begin{array}{l}34 \text { vs. } 60 \\
(p<0.0001)\end{array}$ & $\begin{array}{l}6 \text { vs. } 15 \\
(p=0.033)\end{array}$ & --- & $\mathrm{lb}$ \\
\hline $\begin{array}{l}\text { Van Cutsem 2007/8 (e4), } \\
\text { CRYSTAL } \star^{3}\end{array}$ & 1198 & FOLFIRI vs. FOLFIRI + cetuximab & $\begin{array}{l}38.7 \text { vs. } 46.9 \\
(p=0.0038)\end{array}$ & $\begin{array}{l}1.5 \text { vs. } 4.3 \\
(p=0.0034)\end{array}$ & --- & $\mathrm{lb}$ \\
\hline Saltz $2008^{*^{4}}(e 5)$ & 1401 & $\begin{array}{l}\text { XELOX/FOLFOX } 4 \text { + beva vs. } \\
\text { XELOX/FOLFOX } 4 \text { + placebo }\end{array}$ & 38 vs. $38(p=0.99)$ & N/A & $\begin{array}{l}21.3 \text { vs. } 19.9 \text { months } \\
(p=0.077)\end{array}$ & IV \\
\hline
\end{tabular}

$\star^{2}$ Resection rate as a secondary endpoint, FOLFOXIRI by continuous infusion; $\star^{3}$ Resection rate as a secondary endpoint, benefit only from the treatment of patients with k-ras wildtype tumors; ${ }^{*}$ Resection rates as the result of exploratory subgroup analyses: EBM, evidence-based medicine; N/A, not available 